\title{
Editorial
}

\section{Staging in giant vestibular Schwannoma surgery}

In the manuscript titled "Staging in giant vestibular Schwannoma surgery: A two consecutive day technique for complete resection in basic neurosurgical setups," [1] the authors have represented 12 cases of giant vestibular Schwannomas surgically treated in the Bangur Institute of Neurosciences through a retrosigmoid approach in two stages on two consecutive days after a night in the intensive care unit. They have observed that this technique improves tumor resection for surgeon comfort without major surgical risks in hospitals with basic technology.

Despite the fact that there are many research papers published in the literature about long series with giant vestibular Schwannomas resected in one step, ${ }^{[2-5]}$ it could be an option for hospitals without the latest technological envelope. However, we think the study could be improved with a control group (patients with complete resection in one step in the same conditions) versus two steps in order to clarify its value. Furthermore, we do not advocate the routine use of ventriculoperitoneal shunt 1 week before the surgical resection because the management of cerebrospinal fluid can be controlled using external ventriculostomy during surgery without permanent shunt.

In addition, we would like to emphasize that the goal of giant vestibular Schwannoma surgery is radical

\begin{tabular}{|l|l|}
\hline \multicolumn{2}{|c|}{ Access this article online } \\
\hline Quick Response Code: & Website: \\
\hline & www.ruralneuropractice.com \\
\cline { 2 - 2 } & \\
\hline
\end{tabular}

removal with preservation of facial and lower cranial nerve function; therefore, intraoperative monitoring is necessary to use, and this technique is not related to maintaining facial nerve function, which worsened after surgery and subsequently improved with passing of months. As the authors suggested, further research with longer follow-up as well as with a larger number of patients should be carried out in order to demonstrate the efficaciousness of giant vestibular Schwannoma surgical resection in two steps for these kinds of hospitals.

\section{Isabel Cuervo-Arango Herreros, Álvaro Campero ${ }^{1}$ Department of Neurosurgery, Oviedo Hospital, Asturias, Spain, ${ }^{1}$ Padilla Hospital, Tucumán, Argentina \\ Address for correspondence: Dr. Alvaro Campero, Country Las Yungas, Tucumán, Argentina E-mail: alvarocampero@yahoo.com.ar}

\section{References}

1. Bandlish D, Biswas N, Deb S. Staging in giant vestibular schwannoma surgery: A two consecutive day technique for complete resection in basic neurosurgical setups. J Neurosci Rural Pract 2014;5:225-30.

2. Zou P, Zhao L, Chen P, Xu H, Liu N, Zhao P, et al. Functional outcome and postoperative complications after the microsurgical removal of large vestibular schwannomas via the retrosigmoid approach: A meta-analysis. Neurosurg Rev 2014;37:15-21.

3. Kulwin CG, Cohen-Gadol AA. Technical nuances of resection of giant $(>5 \mathrm{~cm})$ vestibular schwannomas: Pearls for success. Neurosurg Focus 2012;33:E15.

4. Campero A, Martins C, Rhoton A Jr, Tatagiba M. Dural landmark to locate the internal auditory canal in large and giant vestibular schwannomas: The Tübingen line. Neurosurgery 2011;69(Suppl Operative1): Ons99-102.

5. Samii M, Gerganov VM, Samii A. Functional outcome after complete surgical removal of giant vestibular schwannomas. J Neurosurg 2010;112:860-7.

How to cite this article: Herreros IC, Campero A. Staging in giant vestibular Schwannoma surgery. J Neurosci Rural Pract 2014;5:209.

Source of Support: Nil. Conflict of Interest: None declared. 